\title{
Synthesis and Properties of 9-Anthraldehyde Acetal of Poly(vinyl alcohol)
}

\author{
Yasuo Oshiro, Yasuhiko Shirota, and Hiroshi Mikawa \\ Department of Applied Chemistry, Faculty of Engineering, \\ Osaka University, Suita, Osaka, Japan.
}

(Received August 21, 1972)

\begin{abstract}
The 9-anthraldehyde acetal of poly(vinyl alcohol) (abbreviated hereafter as acetal) was synthesized from poly(vinyl alcohol) and 9-anthraldehyde with hydrochloric acid as a catalyst in dioxane-water $(60: 40)$, and the kinetics of the acetalization was examined. The initial rate of the reaction was first order with respect to the initial concentration of poly(vinyl alcohol), 9-anthraldehyde, and acid. The apparent activation energy was calculated as $3.4 \mathrm{kcal} / \mathrm{mol}$. The maximum degree of acetalization did not exceed $43.8 \%$. The low degree of acetalization was interpreted in terms of steric hindrance by the anthracene ring. Acetylation of the acetal gave acetylated acetal which was easily soluble in organic solvents, although the original acetal was almost insoluble in organic solvents. The charge-transfer complex of the acetylated acetal with tetracyanoquinodimethane (TCNQ) showed a charge-transfer absorption band with $\lambda_{\max }$ $730 \mathrm{~nm}$ in methylene chloride at room temperature. The equilibrium constant $(K)$ was evaluated as $15.71 / \mathrm{mol}$. The dielectric constants $(\varepsilon)$ measured at $1 \mathrm{kHz}$ were 3.1 for the acetylated acetal film, and 2.9 for the charge-transfer complex of the acetylated acetal with TCNQ.

KEY WORDS Poly(vinyl alcohol) / 9-Anthraldehyde / Acetal / Acetalization / Tetracyanoquinodimethane / Charge-Transfer Complex / Dielectric Constant /
\end{abstract}

Polymers having a high dielectric constant have been reported by many authors, but most of the compounds are polar polymers having dielectric constants mainly due to dipole orientation.

Recently, Saito, et al., ${ }^{1}$ reported that the dielectric constant of $p$-aminostyrene-methylacrylate copolymer increased when complexed with an electron acceptor such as p-chloranil. The mechanism of this increase in dielectric constant, however, is not clear.

Because of our interest in the dielectric properties of such polymers, we attempted to investigate a polymer having electron-donating side groups capable of forming stable chargetransfer complexes with electron-acceptor molecules. As the most convenient method to introduce electron-donating side groups into a polymer chain, we took up the acetalization reaction of poly(vinyl alcohol) with polyacene aldehydes such as 9-anthraldehyde. The 9-anthraldehyde acetal of poly(vinyl alcohol) (abbreviated as acetal) so far has been reported only as a photopolymer in a patent $\mathrm{t}^{2}$, and details of the synthetic conditions as well as its properties are not known.

This paper deals with the reaction of poly(vinyl alcohol) with 9-anthraldehyde to synthesize the 9-anthraldehyde acetal of poly(vinyl alcohol), the acetylation of the acetal, and the chargetransfer interaction of the acetylated acetal with tetracyanoquinodimethane. In addition, preliminary results of the dielectric properties of the acetylated acetal film, and the acetylated acetal film complexed with tetracyanoquinodimethane are briefly described.

\section{EXPERIMENTAL}

\section{Materials}

Poly(vinyl alcohol) was obtained commercially, washed with methanol several times and dried under reduced pressure. (Saponification degree $99 \%$, average degree of polymerization 300-700.)

9-Anthraldehyde was synthesized from anthracene by the Vilsmeier-Haack reaction, and 
recrystallized from methanol, $\mathrm{mp} 107-108^{\circ} \mathrm{C}$.

Dioxane, acetic anhydride, and methylene chloride were used after ordinary purifications.

Tetracyanoquinodimethane (TCNQ) was commercially available, recrystallized from acetonitrile and sublimed.

Anthracene was used as a model compound for measuring the charge-transfer band with TCNQ and its equilibrium constant. The anthracene was purified by passing its benzene solution through an alumina column to make free from naphthacene, followed by recrystallization from methanol and vaccum sublimation.

The 9-anthraldehyde acetal of 2,4-pentanediol was synthesized from 2,4-pentanediol and 9-anthraldehyde with sulfuric acid as the catalyst in a benzene solution at $80^{\circ} \mathrm{C}: \mathrm{mp} 172^{\circ} \mathrm{C}$; mass spectrum, $\mathrm{M}^{+}=292$. Calcd for $\mathrm{C}_{20} \mathrm{H}_{20} \mathrm{O}_{2}=292.4$. Found: $\mathrm{C}, 82.35 ; \mathrm{H}, 6.57$. Calcd for $\mathrm{C}_{20} \mathrm{H}_{20} \mathrm{O}_{2}$ : C, 82.15; H, 6.89 .

\section{Typical Procedure of Acetal Synthesis}

Polyvinyl alcohol, $1.1 \mathrm{~g}(0.025 \mathrm{~mol})$, and 9anthraldehyde, $3.03 \mathrm{~g}(0.015 \mathrm{~mol})$, were dissolved in dioxane-water $(60: 40)$, and the solution was kept at $60^{\circ} \mathrm{C}$. Hydrochloric acid $(12 N), 1.0 \mathrm{~g}$, was added with stirring as a catalyst. After several hours the reaction solution was poured into a large amount of water and neutralized with a 10-\% solution of sodium carbonate. The precipitated polymer was filtered, washed first with water, then with methanol to remove unreacted 9-anthraldehyde, and dried under reduced pressure to give a white solid mass, $\mathrm{mp} 230^{\circ} \mathrm{C}$. The polymer was almost insoluble in ordinary organic solvents.

Acetylation of 9-Anthraldehyde Acetal of Poly(vinyl alcohol)

Acetylation of the hydroxyl groups remaining in the acetal was carried out by the method of W. O. Herrman ${ }^{3}$. The acetal $(0.5 \mathrm{~g})$ and anhydrous sodium acetate $(2.5 \mathrm{~g})$ were refluxed in $40 \mathrm{ml}$ acetic anhydride for $4 \mathrm{hr}$, and the solution was poured into a large amount of water. The precipitated polymer was filtered, washed with water several times, dried, and reprecipitated from methylene chloride- $n$-hexane. The acetylated acetal was easily soluble in organic solvents such as dioxane, methylene chloride, acetone, or alcohol. IR spectrum: $\nu_{\mathrm{C}=0} 1730 \mathrm{~cm}^{-1}$ (acetate moiety), $\nu_{\mathrm{C}-\mathrm{O}} 1250 \mathrm{~cm}^{-1}$ (acetal moiety), $\nu_{\mathrm{C}-0-\mathrm{C}}$ $1110 \mathrm{~cm}^{-1}$ (acetal moiety), $\delta_{\mathrm{C}-\mathrm{H}} 890,730 \mathrm{~cm}^{-1}$ (anthracene moiety), $\delta_{\mathrm{C}=\mathrm{C}} 1630 \mathrm{~cm}^{-1}$ (anthracene moiety), $820 \mathrm{~cm}^{-1}$ (skeletal vibration of acetal ring ${ }^{4}$ ). UV spectrum: $\lambda_{\max } 257 \mathrm{~nm}, 330-383 \mathrm{~nm}$. $\left(\pi-\pi^{*}\right.$ transition of anthracene, moiety.) NMR spectrum: $\tau 8.60$ (multiplet, $\mathrm{CH}_{2}$ in acetal ring), $\tau 8.20$ (multiplet, $\mathrm{CH}_{2}$ ), $\tau 7.95$ (singlet, $\mathrm{CO}-\mathrm{CH}_{3}$ ), $\tau 6.40$ (broad, $\stackrel{\mathrm{O}}{\mathrm{O}}_{>\mathrm{CH} \text {-anthracene), } \tau} 5.15$ (multiplet, -CH-OCO-).

Found: C, 68.82; H, 6.76. Calcd for an acetylated acetal with a 38.9-\% degree of acetalization: C, 69.35; H, 6.38.

Rate Measurements of the Acetalization Reaction

The measurement of the reaction rate was carried out by titration of the unreacted aldehyde with sodium borohydride ${ }^{9}$ according to the following chemical equations.

$$
\begin{aligned}
& 4 \mathrm{RCHO}+\mathrm{NaBH}_{4}=\mathrm{NaB}\left(\mathrm{OCH}_{2} \mathrm{R}\right)_{4} \\
& \mathrm{NaB}\left(\mathrm{OCH}_{2} \mathrm{R}\right)_{4}+2 \mathrm{NaOH}+\mathrm{H}_{2} \mathrm{O}=\mathrm{Na}_{3} \mathrm{BO}_{3} \\
& +4 \mathrm{RCH}_{2} \mathrm{OH} \\
& 3 \mathrm{BH}_{4}{ }^{-}+4 \mathrm{IO}_{3}{ }^{-} \rightarrow 4 \mathrm{I}^{-}+3 \mathrm{H}_{2} \mathrm{BO}_{3}^{-}+3 \mathrm{H}_{2} \mathrm{O} \\
& \mathrm{KIO}_{3}+5 \mathrm{KI}+3 \mathrm{H}_{2} \mathrm{SO}_{4}=3 \mathrm{~K}_{2} \mathrm{SO}_{4} \\
& +3 \mathrm{I}_{2}+3 \mathrm{H}_{2} \mathrm{O} \\
& \mathrm{NaBH}_{4}(\mathrm{mg})=\left[N F\left(\mathrm{ml} \text { of } \mathrm{KIO}_{3}\right)\right. \\
& \left.\quad-N^{\prime} F^{\prime}\left(\mathrm{m} l \text { of } \mathrm{Na}_{2} \mathrm{~S}_{2} \mathrm{O}_{3}\right)\right] \times 37.83 / 8 \\
& \text { Aldehyde }(\mathrm{mg})=\left(\mathrm{mg} \text { of } \mathrm{NaBH}_{4}\right) \\
& \times(M W \text { of aldehyde })(4 / 37.83)
\end{aligned}
$$

Aliquots of the reaction solution were withdrawn by a $5-\mathrm{m} l$ pipet at appropriate time intervals, and added to a $10-\mathrm{m} l$ aqueous solution of $0.5-N$ sodium hydroxide containing $25 \mathrm{mg}$ of sodium borohydride. After $1 \mathrm{hr}$ a $20-\mathrm{ml}$ solution of $0.25-\mathrm{N} \mathrm{KIO}_{3}, 2 \mathrm{~g}$ of $\mathrm{KI}$, and then $4-\mathrm{N} \mathrm{H}_{2} \mathrm{SO}_{4}$ were added to the above solution. The solution was allowed to stand for $5 \mathrm{~min}$ in the dark and then titrated with $0.1-N$ sodium thiosulfate.

\section{Measurements}

A Hitach 124 spectrophotometer was used for the measurements of the absorption spectra. The IR spectra were taken with a Hitach EPIG2-infrared spectrometer. The NMR spectra were measured in hexadeuterio acetone with TMS as an internal standard using a Japan Electron 
Optics Laboratory JNM-3H-60 spectrometer.

Measurements of the dielectric constant and dielectric loss were carried out with G. R. Capacitance Bridge Type $1615 \mathrm{~A}$ at room temperature. Samples of films $10 \times 10 \times 10^{-3} \mathrm{~mm}$ were prepared by the solvent-cast method and were submitted for measurements.

\section{RESULTS AND DISCUSSION}

Synthesis of the 9-Anthraldehyde Acetal of Poly(vinyl alcohol)

The acetal was synthesized from poly(vinyl alcohol) and 9-anthraldehyde with hydrochloric acid as a catalyst in dioxane-water $(60: 40)$ at $60^{\circ} \mathrm{C}$. Under these conditions the reaction proceeded homogeneously. The degree of acetaliza- tion of the obtained acetal varied greatly with reaction conditions (Table $\mathrm{I}$ ). The acetals obtained under various reaction conditions were white solid masses with softening points above $190^{\circ} \mathrm{C}$. Since they were almost insoluble in ordinary organic solvents, characterizations of the acetals were made by using the method by Herrman $^{3}$ to acetylate the hydroxyl groups remaining in the polymer. The such acetylated acetals thus obtained became soluble in organic solvents such as dioxane, methylene chloride, acetone or alcohol, although they were insoluble in $n$-hexane, or carbon tetrachloride. The softening point of the acetylated acetal was raised with an increase in the acetalization degree (A.D.); e.g., $107^{\circ} \mathrm{C}$ for $8-\%$ A.D., $127^{\circ} \mathrm{C}$ for 20-\% A.D., and $137^{\circ} \mathrm{C}$ for $38.6-\%$ A.D..
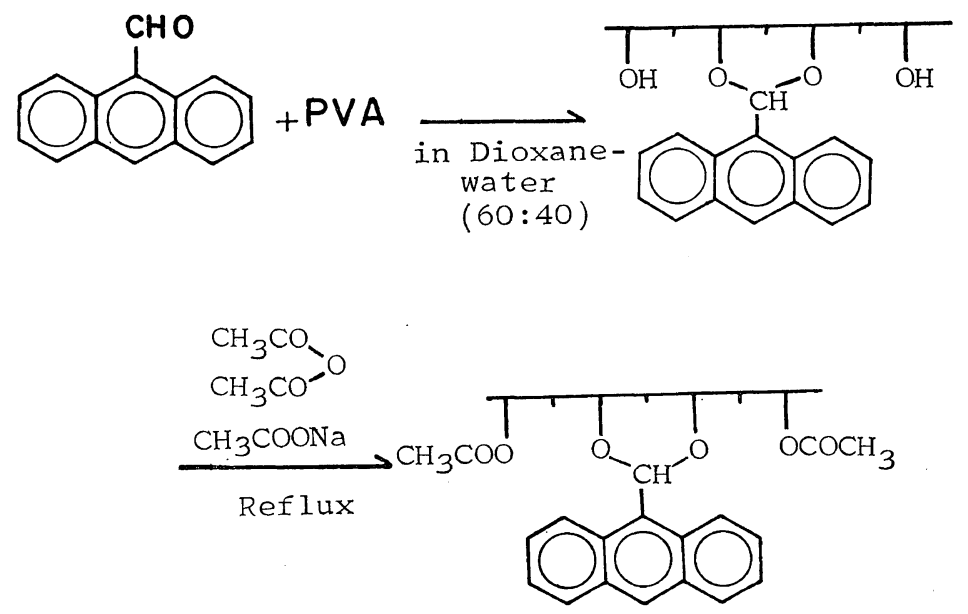

Table I. Acetalization degree of the 9-anthraldehyde acetal of poly(vinyl alcohol) (PVA) ${ }^{a}$

\begin{tabular}{|c|c|c|c|c|c|c|c|c|}
\hline \multirow{2}{*}{ No. } & \multirow{2}{*}{$\begin{array}{c}\text { PVA, } \\
10^{-1} \mathrm{~mol} / \mathrm{l}\end{array}$} & \multirow{2}{*}{$\begin{array}{l}\text { Aldehyde, } \\
\text { equiv/PVA }\end{array}$} & \multirow{2}{*}{$\begin{array}{l}\text { Acid, } \\
\mathrm{mol} / \mathrm{l}\end{array}$} & \multirow{2}{*}{$\underset{{ }^{\circ} \mathrm{C}}{\text { Temp }}$} & \multirow{2}{*}{$\begin{array}{c}\text { Time, } \\
\text { hr }\end{array}$} & \multicolumn{2}{|c|}{ Elementary analysis } & \multirow{2}{*}{$\begin{array}{c}\text { Acetalization } \\
\text { degree, } \%{ }^{\mathrm{b}}\end{array}$} \\
\hline & & & & & & $\mathrm{C}, \%$ & $\mathrm{H}, \%$ & \\
\hline 1 & 2.5 & 0.9 & 0.6 & 60 & 4 & 60.14 & 7.50 & 10.7 \\
\hline 2 & 2.5 & 1.7 & 1.2 & 60 & 12 & 66.86 & 7.57 & $20.1^{\mathrm{c}}$ \\
\hline $3^{d}$ & & 1.7 & 1.2 & 60 & 12 & 74.44 & 6.80 & $43.8^{c}$ \\
\hline 4 & 2.5 & 2.4 & 1.2 & 60 & 30 & 68.82 & 6.60 & 37.1 \\
\hline 5 & 2.5 & 2.9 & 1.2 & 60 & 48 & 68.82 & 6.86 & 37.1 \\
\hline 6 & 2.5 & 1.2 & 1.2 & 60 & 24 & 62.59 & 7.19 & 17.4 \\
\hline
\end{tabular}

a When the concentration of the aldehyde and the acid was below 1 equiv/PVA and $0.6 \mathrm{~mol} / \mathrm{l}$, respectively, the acetalization degree was much lower.

b The acetalization degree was calculated from carbon content $(\mathrm{C} \%)$ in elementary analyses of the acetylated acetal. A.D. $=(86 \mathrm{C}-48) \times 100 /(66-0.52 \mathrm{C}),(\mathrm{C}, \%$ of carbon content $)$.

c The acetalization degree was calculated from $\mathrm{C} \%$ in the elementary analyses of the acetal. A.D.= $(44 \mathrm{C}-24) \times 100 /(90-0.92 \mathrm{C})$.

d Reacetalization of the acetal obtained in expt no. 2. 


\section{Acetalization Degree}

The acetalization degree was determined from the elementary analyses of the acetylated acetal. Generally, the acetalization degree increased with increasing concentration of the aldehyde and catalyst. Some results are shown in Table I. It is noteworthy that the maximum acetalizationdegree did not go over $40 \%$ for any reaction conditions examined. Although reacetalization of the acetal was carried out, the acetalization degree did not exceed $43.8 \%$. Flory ${ }^{5}$ reported the value $84.46 \%$ as the maximum acetalization- degree based on a statistical calculation. Thus, the maximum acetalization-degree in the reaction of poly(vinyl alcohol) with, e.g., benzaldehyde has been reported to reach $85 \% .^{6}$ The marked low acetalization-degree observed with 9-anthraldehyde in the present study is interpreted as due to the steric hindrance of the bulky anthracene ring.

\section{Kinetics of the Acetalization Reaction}

The rate of the reaction was measured from the quantity of aldehyde consumed in the reaction. Figures $1-3$ show the dependence of the
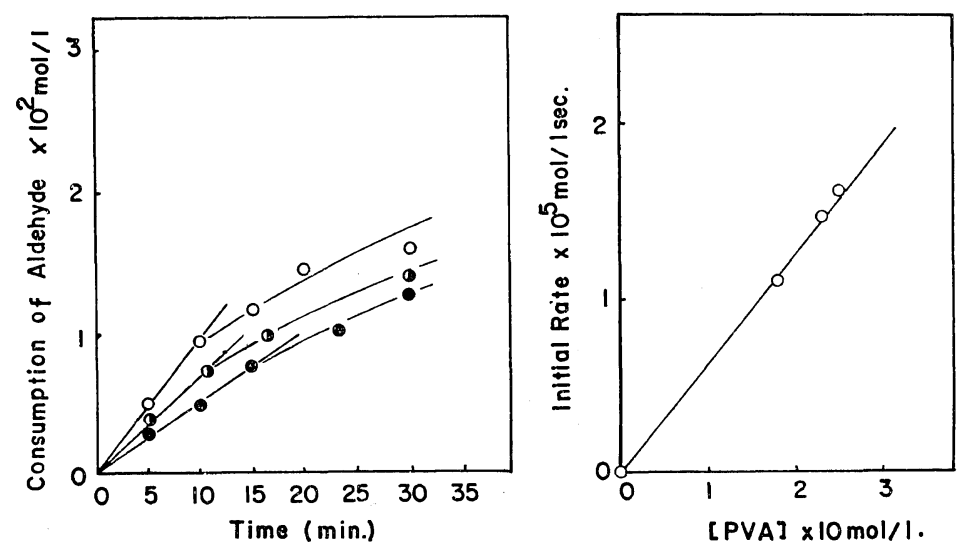

Figure 1. Dependence of the initial rate on the initial concentration of poly(vinyl alcohol) (PVA) at $60^{\circ} \mathrm{C}$; [9-anthraldehyde] $=1.0 \times 10^{-1} \mathrm{~mol} / l$, [acid] $=1.2 \mathrm{~mol} / l$. Concentration of poly(vinyl alcohol) calculated on the basis of the monomer unit: $\bigcirc, 2.5 \times 10^{-1} \mathrm{~mol} / l ;$, $2.2 \times 10^{-1} \mathrm{~mol} / l ; \quad, 1.8 \times 10^{-1} \mathrm{~mol} / l$.
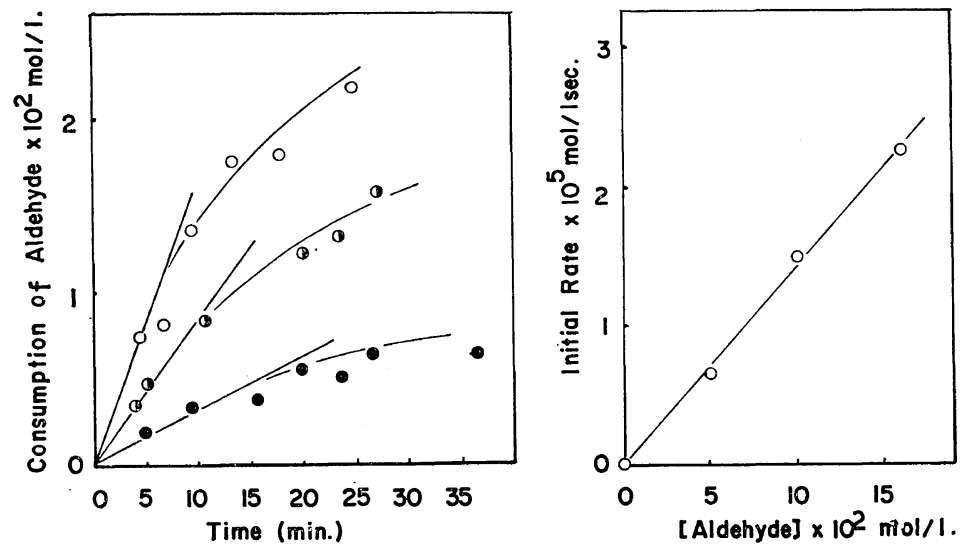

Figure 2. Dependence of the initial rate on the initial concentration of 9-anthraldehyde at $60^{\circ} \mathrm{C} ;[\mathrm{PVA}]=2.5 \times 10^{-1} \mathrm{~mol} / l$, [acid] $=1.2 \mathrm{~mol} / l$.

Concentration of 9-anthraldehyde:

$\bigcirc, 1.5 \times 10^{-1} \mathrm{~mol} / l ; 1.0 \times 10^{-1} \mathrm{~mol} / l ; 0,5.0 \times 10^{-2} \mathrm{~mol} / l$. 

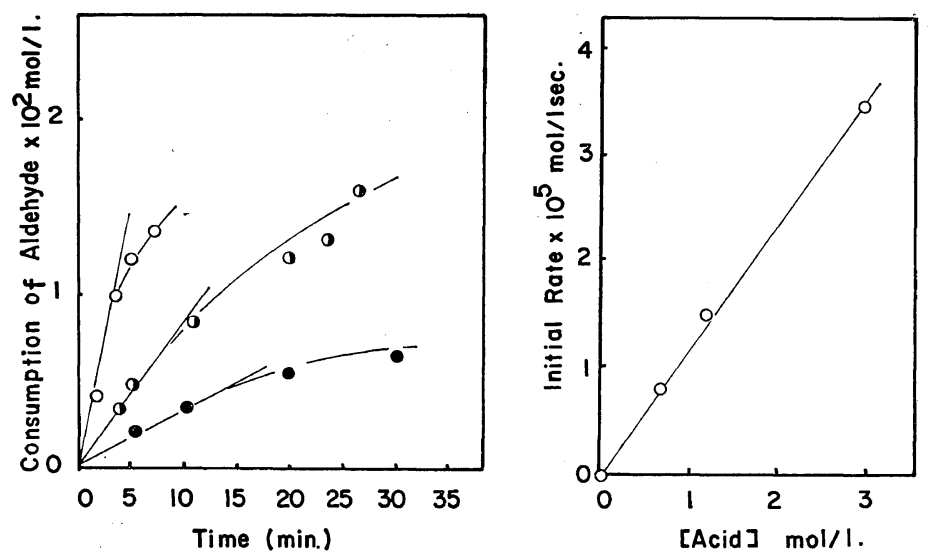

Figure 3. Dependence of the initial rate on the initial concentration of acid at $60^{\circ} \mathrm{C}: \quad[\mathrm{PVA}]=2.5 \times 10^{-1} \mathrm{~mol} / l ;$; 9 -anthraldehyde $]=1.0 \times 10^{-1} \mathrm{~mol} / l$.

Concentration of hydrochloric acid:

$\bigcirc, 2.8 \mathrm{~mol} / l ;$. $1.2 \mathrm{~mol} / l ; \bullet, 0.6 \mathrm{~mol} / l$.

initial rate of acetalization on the varying concentration :of alcohol, aldehyde, and acid, respectively. The initial rate of acetalization followed first-order kinetics with respect to the initial concentration of alcohol, aldehyde, and acid. From variations of the reaction temperature the apparent activation-energy of the reaction was calculated as $3.4 \mathrm{kcal} / \mathrm{mol}$.

The acetalization of poly(vinyl alcohol) with 9-anthraldehyde carried out in dioxane-water$(60: 40)$ may be interpreted by a mechanism similar to that first presented by Ogata, et al. ${ }^{7}$ for the formation of the formal of poly(vinyl alcohol).<smiles>[R]C(O)CC(O)CC(O)C(CC)OC(CC)CC(C)O</smiles>

(3)<smiles>[R]COC(CC)CC(C)O</smiles><smiles>[R]C([PH2+])OC(C)CC(CC)OCC</smiles>

Reaction (2) being a rate-determining step, the rate of acetalization can be expressed by the equation

$$
\begin{aligned}
\text { Rate } & =\mathrm{d}[\text { Acetal }] / \mathrm{d} t=-\mathrm{d}[\text { Aldehyde }] / \mathrm{d} t \\
& =k\left[\mathrm{RC}^{+} \mathrm{HOH}\right][\text { PVA }] \\
& =k^{\prime}[\text { Aldehyde }][\text { Acid }][\text { PVA }],
\end{aligned}
$$

which is in good agreement with the experimental results.

The low value of the acetalization degree suggests that the reaction occurs preferentially at the isotactic hydroxyl groups in poly(vinyl alcohol). This might be responsible for the relatively low activation-energy of the reaction, since isotactic poly(vinyl alcohol) groups are known to be more reactive than atactic or syndiotactic ones. ${ }^{8}$ The poly(vinyl alcohol) used in present study is known to have 55-\% isotactic hydroxyl groups and $45-\%$ syndiotactic ones (dyad). Also, it is generally accepted that the formation of isolated hydroxyl groups which can no longer react with aldehyde is responsible for the low acetalizationdegree. The formation of isolated hydroxyl groups seems to be striking in the present acetali- 



Figure 4. Dependence of the initial rate on the reaction temperature: [PVA]= $2.5 \times 10^{-1} \mathrm{~mol} / l ;\left[9\right.$-anthraldehyde] $=1.0 \times 10^{-1} \mathrm{~mol} / l ;$ [acid] $=1.2 \mathrm{~mol} / l$.

Reaction temperature:

$\bigcirc, 47^{\circ} \mathrm{C} ; 0,60^{\circ} \mathrm{C} ; 0,83^{\circ} \mathrm{C}$.

zation reaction because of the steric hindrance by the bulky anthracene ring.

The rate of the acetalization deviated from linearity even in the early reaction stage as can be seen in Figures $1-3$. This deviation in the early reaction stage may be interpreted by taking account of the isolated hydroxyl groups remaining in the polymer chain. That is, the formation of isolated hydroxyl groups may be appreciable even in the early stages of the reaction because of the bulky anthracene ring in the aldehyde, so that the number of hydroxyl groups accessible to the acetalization reaction decreases rapidly as the reaction proceeds.

Charge-Transfer Interaction between the Acetylated Acetal and Tetracyanoquinodimethane

The charge-transfer interaction between the acetylated acetal (I) and TCNQ was studied and compared with the TCNQ chage-transfer complexes of anthracene and the 9-anthraldehyde acetal of 2,4-pentanediol (II).

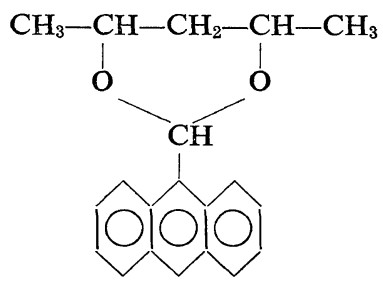

When the acetylated acetal was mixed with TCNQ in methylene chloride, a new broad band

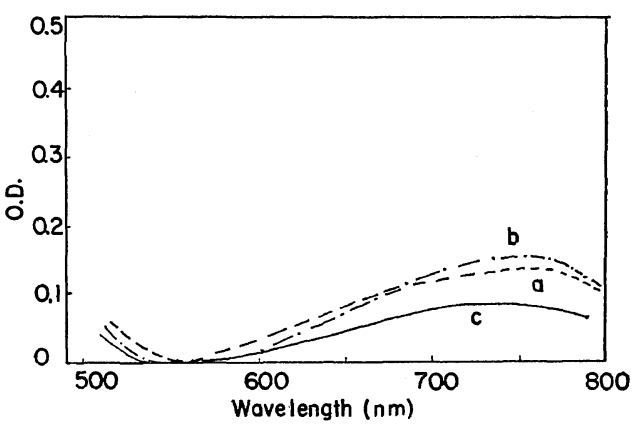

Figure 5. Absorption Spectra of the systems a, b, and $\mathrm{c}$ in methylene chloride at room temperature: a, anthracene-TCNQ, [anthracene] $=1.95 \times 10^{-2}$ $\mathrm{mol} / l, \quad[\mathrm{TCNQ}]=5.71 \times 10^{-3} \mathrm{~mol} / l ; \quad$ b, 9-anthraldehyde acetal of 2,4-pentanedio1-TCNQ, [9-anthraldehyde acetal of 2,4-pentanediol] $=4.61 \times 10^{-2} \mathrm{~mol} / l$, $[\mathrm{TCNQ}]=8.50 \times 10^{-4} \mathrm{~mol} / l ; \mathrm{c}$, the acetylated acetalTCNQ, [the acetylated acetal] $=1.04 \times 10^{-2} \mathrm{~mol} / l$, $[\mathrm{TCNQ}]=1.07 \times 10^{-3} \mathrm{~mol} / l$.

ascribable to the charge-transfer absorption between the anthracene ring in the polymer and TCNQ appeared at $\lambda_{\max } 730 \mathrm{~nm}$. This absorption band was stable at room temperature and did not change with time. The charge-transfer absorption bands of the systems (II)-TCNQ, and anthracene-TCNQ appeared at $\lambda_{\max } 750$ and 760 $\mathrm{nm}$, respectively in methylene chloride (Figure 5).

Equilibrium constants $(K)$ and molar extinction coefficients $(\varepsilon)$ of these complexes were calculated from their Bensi-Hildebrand plots. The results 
Synthesis and Properties of 9-Anthraldehyde Acetal of Poly(vinyl alcohol)

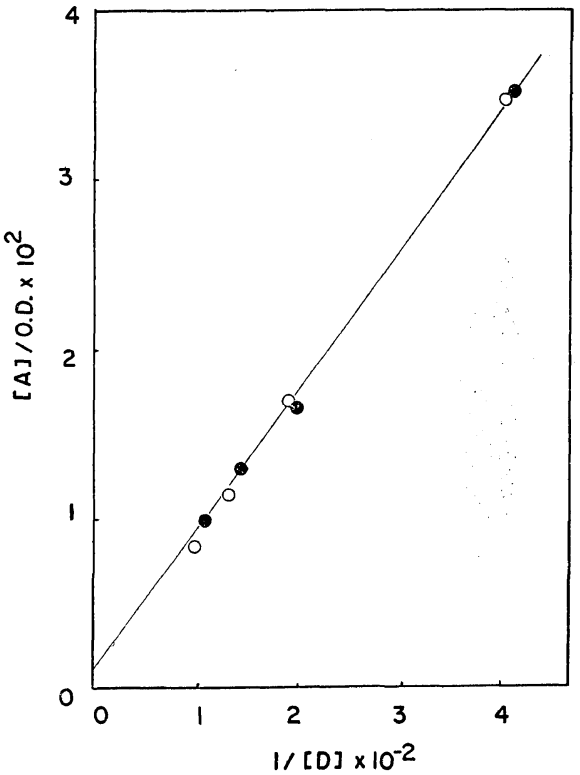

Figure 6. Benesi-Hildebrand plot for the complex of the acetylated acetal-TCNQ at $730 \mathrm{~nm}$ :

, for the acetylated acetal of $14.7-\%$ acetalization degree, [acetylated acetal] $=1.05 \times 10^{-2}-2.48 \times$ $10^{-3} \mathrm{~mol} / l$, [TCNQ] $=1.06 \times 10^{-3} \mathrm{~mol} / l ; \bigcirc$, for the acetylated acetal of $17.4-\%$ acetalization degree, [acetylated acetal] $=1.30 \times 10^{-2}-2.6 \times 10^{-3} \mathrm{~mol} / l$, $[\mathrm{TCNQ}]=1.07 \times 10^{-3} \mathrm{~mol} / l ; K=15.7 ; \varepsilon=770$.

are shown in Figures 6 and 7. The value $K$ obtained for the acetylated acetal (I)-TCNQ system was 15.7 , while that of the anthraceneTCNQ system was 5.56. For the (II)-TCNQ system $K$ was found to be 15.5 . Therefore, the large equilibrium constant obtained for the acetylated acetal as compared with that for anthracene does not seem to be due to the substance being a polymer, but due to the electrondonating effect of the acetal ring.

\section{Dielectric Properties}

The dielectric constants measured at $1 \mathrm{kHz}$ were 3.1 for the acetylated acetal (acetalization degree 10\%), and 2.9 for the charge-transfer complex of the same acetal with TCNQ (TCNQ $1 \mathrm{wt} \%)$. Frequency dependence of the dielectric constant $\left(\varepsilon^{\prime}\right)$ and dielectric loss $\left(\varepsilon^{\prime \prime}\right)$ are shown in Figure 8.

Contrary to the substance investigated by Saito, et al.," the dielectric constant of the acetylated acetal was not increased by the for-

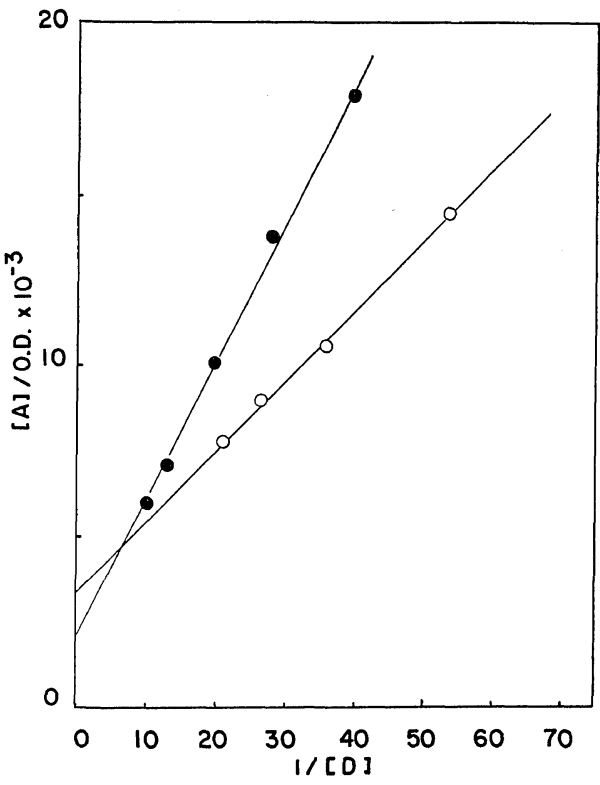

Figure 7. Benesi-Hildebrand plot for (a) anthracene-TCNQ and (b) (II)-TCNQ:

-(a),[anthracene] $=1 \times 10^{-1}-2.5 \times 10^{-2} \mathrm{~mol} / l$, [TCNQ] $=2.4 \times 10^{-3} \mathrm{~mol} / l, \quad K=5.56, \quad \varepsilon=455 ; \bigcirc(\mathrm{b}), \quad[(\mathrm{II})]$ $=4.61 \times 10^{-2}-9.2 \times 10^{-3} \mathrm{~mol} / l, \quad[\mathrm{TCNQ}]=4.25 \times 10^{-3}$ $\mathrm{mol} / l, K=15.5, \varepsilon=290$.



Figure 8. Dielectric constant and loss vs. frequency curve:

-, the acetylated acetal film; $\bigcirc$, the charge-transfer complex of the same acetal with TCNQ (TCNQ $1 \mathrm{wt} \%$ ).

mation of a charge-transfer complex. Additionally, in a poly(vinylcarbazole)-polystyrene-blended film, the dielectric constant was not increased 
by complexation with TCNQ, the values obtained at $1 \mathrm{kHz}$ being 2.5 and 2.3 before and after the complex formation $(1 \mathrm{wt} \%)$, respectively.

Acknowledgment. The authors wish to thank Mr. T. Shiba of Nippon Electric Company for measurements of dielectric properties.

\section{REFERENCES}

1. T. Sawamura and S. Saito, Reprint, SPSJ 20th Annual Meeting, Tokyo, Japan, May, 1971, 2, p 405.
2. DROP 942779 (1953).

3. W. O. Herrman, Ber., 60, 1658 (1927).

4. H. C. Beachell, P. Fotis, and J. Hucks, J. Polym. Sci., 7, 353 (1951).

5. P. J. Flory, J. Amer. Chem. Soc., 72, 5052 (1950).

6. K. Noma, T. Ou, and T. Tokita, Kobunshi Kagaku (Chem. High Polymers), 6, 439 (1949).

7. Y. Ogata, M. Okano, and T. Ganke, J. Amer. Chem. Soc., 78, 2962 (1956).

8. I. Sakurada, Y. Sakaguchi, and J. Shiiki, Kobunshi Kagaku (Chem. High Polymers), 21, 289 (1964).

9. E. H. Jensen and W. A. Struck, Anal. Chem., 24, 1843 (1952). 